\title{
Identification of Position DC Motor and Control Using Fuzzy Type - 2 Based PSO
}

\author{
Mohammed Z. Al-Faiz, ${ }^{1}$ Ahmed A. Oglah, ${ }^{2}$ \\ Computer Eng. Dept. ,Nahrain University, Baghdad ,Iraq \\ mzalfaiz12@gmail.com
}

Control \&Systems Eng. Dept., University of Technology, Baghdad ,Iraq ahmedalaa1975@yahoo.com

\begin{abstract}
This paper presents identification of a position DC motor using least - squares analysis to estimate the parameters of an ARX model .Type-2 fuzzy logic controllers is proposed as an alternative solution in the literature when a system has a large amount of uncertainties. This paper proposed an algorithm of interval fuzzy type -2 logic controller(PSOIT2FLC)with the optimized parameters using particle swarm optimization in the design of fuzzy controller for the position control of DC Motor. The performance of the proposed PSOIT2FLC is compared with that of its corresponding conventional PSO algorithm type -1 FLC in terms of several performance measures such as rise time, peak overshoot, settling time, integral absolute error (IAE) and integral of time multiplied absolute error (ITAE) and in each case, the proposed scheme shows improved performance over its conventional counterpart. . Extensive simulation studies are conducted to compare the response of the given system with the conventional genetic algorithm type -1 fuzzy controller to the response given with the proposed PSOIT2FLC scheme. Simulation works in MATLAB environment demonstrate that the PSO optimized fuzzy position controller became very strong, gives better results and possesses good robustness.
\end{abstract}

Keywords: Type-2 fuzzy Logic Controller; Particle Swarm Optimization; DC Motor; system identification Toolbox.

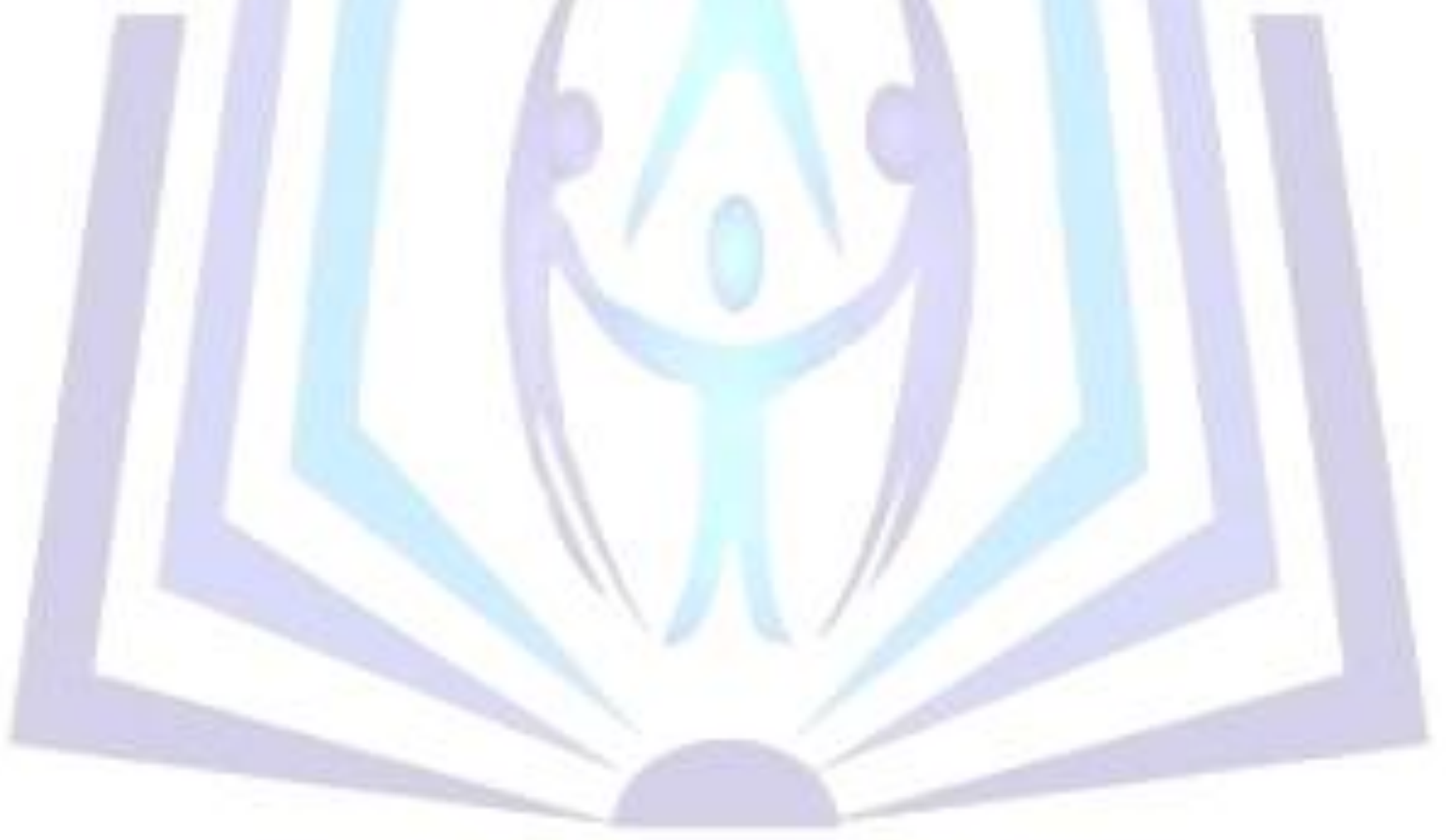

\section{Council for Innovative Research}

Peer Review Research Publishing System

Journal: INTERNATIONAL JOURNAL OF COMPUTERS \& TECHNOLOGY

Vol 11, No. 1

editor@cirworld.com

www.cirworld.com, member.cirworld.com 


\section{I.INTRODUCTION}

Type-2 fuzzy sets was introduced by Zadeh in 1975 [1] as an extension of the type-1 set. A type-2 fuzzy set is characterized by a concept called footprint of uncertainty (FOU).Consequently, the membership grade of each element in a type-2 fuzzy set is a fuzzy set in [0,1], unlike a type-1 set where the membership grade is a crisp number in [0,1]. Fuzzy logic systems (FLSs) constructed using type-2 fuzzy sets are type-2 FLSs to distinguish them from the traditional type-1 FLSs. Fig. 1 shows the schematic diagram of a type-2 FLS. Atype-reducer is needed toconvert the type-2 fuzzy output sets into type- 1 sets before they are processed by the defuzzifier to give a crisp output. Since type-2 FLSs provide an extra mathematical dimension compared with type-1 FLSs, they are very useful in circumstances where it is difficult to determine an exact membership grade for a fuzzy set. Hence, they can be used to handle more system uncertainties and have the potential to outperform their type-1 counterparts. The FLCs have been applied to many areas, especially for the control of complex nonlinear systems that are difficult to model analytically [2]. Despite their popularity, research has shown that type-1 FLCs may have difficulties in modeling and minimizing the effect of uncertainties [3]. This limitation may restrict the usefulness of design methods that tune the FLCs using a Particle Swarm Optimization "PSO" algorithms and a model of the controlled process. Since it is impossible for a model to capture all the characteristics of the actual plant, the performance of a controller designed using a model will inevitably deteriorate when it is applied to the practical system. A controller takes fully into account the non-linear ties. Emerging intelligent techniques have been developed and extensively used to improve or to replace conventional control technique because these techniques do not require a precise model. One of intelligent technique, fuzzy logic by Zadeh is applied for controller design in many applications. The advantage of fuzzy control methods [4] is the fact that they are not sensitive to the accuracy of the dynamical model. With the development of T2 FLSs and their ability to handle uncertainty, utilizing type-2 FLCs (IT2 FLCs) has attracted a lot of interest in recent years. The concept of type-2 fuzzy sets was first introduced by Zadeh as an extension of the concept of well-known ordinary fuzzy sets, type-1 fuzzy sets. A type-2 fuzzy set [5] is characterized by a fuzzy membership function i.e. the membership grade for each element isalso a fuzzy set in [0,1], unlike a type-1 fuzzy set ,where the membership grade is a crisp number in $[0,1]$.The membership functions of type-2 fuzzy sets are three dimensional and include a footprint of Uncertainty(FOU), which is the new third dimension of type-2 fuzzy sets. The footprint of uncertainty provides an additional degree of freedom to handle uncertainties. In this paper, the application of type-2 fuzzy logic concepts to the position control of a simple dc motor is illustrated. The device model is straightforward and the physical implications of position control are readily perceived.

\section{II.DC MOTOR IDENTIFICATION USING ARX MODEL}

Before identification can be applied, the plant model is first derived from the measured input and output signals of a real DC-motor. The PC with the Advantech I/O PCI card 1712 and the Mat lab and Simulink environment serves as the main control unit[7]. Figure 1 show the block diagram of system interfacing unit

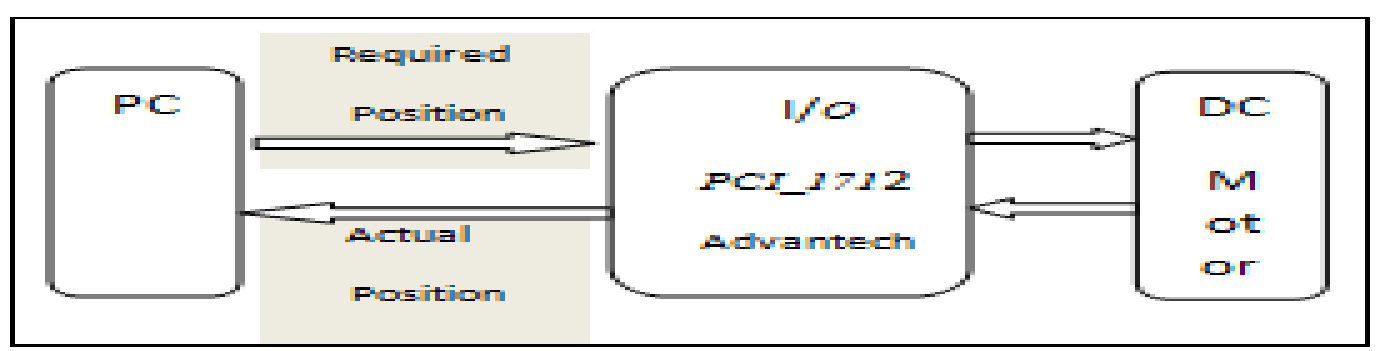

Figure 1: System block diagram

used to collect input-output data. Due to the dynamics of this plant is not too complex, As far as the discrete models are concerned, the most suitable structure choice for DC motor is ARX model. The ARX block uses least-squares analysis to estimate the parameters of an ARX model.

\section{- ARX Model Definition}

The ARX model is defined, as follows:

$$
\mathrm{y}(\mathrm{t})+\mathrm{a}_{1} \mathrm{y}(\mathrm{t}-1)+\cdots . .+\mathrm{an}_{\mathrm{a}} \mathrm{y}\left(\mathrm{t}-\mathrm{n}_{\mathrm{a}}\right)=\mathrm{b}_{1} \mathrm{u}(\mathrm{t}-1)+\cdots . .+\mathrm{bn}_{\mathrm{b}} \mathrm{u}\left(\mathrm{t}-\mathrm{n}_{\mathrm{k}}+\mathrm{n}_{\mathrm{b}}+1\right)+\mathrm{e}(\mathrm{t})
$$

\section{Where}

- $y(t)$ is the output at time ., $a_{1} \ldots . a_{n \&} b_{1} \ldots b_{n}$ are the parameters to be estimated.

- $n_{a}$ is the number of poles of the system., $n_{b}-1$ is the number of zeros of the system.

- $\mathrm{n}_{\mathrm{k}}$ is the number of input samples that occur before the inputs that affect the current output.

$\cdot y(t-1) \ldots y\left(t-n_{a}\right)$ are the previous outputs on which the current output depends.

$\cdot \mathrm{u}\left(\mathrm{t}-\mathrm{n}_{\mathrm{k}}\right) \ldots \mathrm{u}\left(\mathrm{t}-\mathrm{n}_{\mathrm{k}-} \mathrm{n}_{\mathrm{b}}+1\right)$ are the previous inputs on which the current output depends. 
- $e(t)$ is a white-noise disturbance value.The ARX model can also be written in a compact way

using the following notation:

$\mathrm{A}(\mathrm{q}) \mathrm{y}(\mathrm{t})=\mathrm{B}(\mathrm{q}) \mathrm{u}\left(\mathrm{t}-\mathrm{n}_{\mathrm{R}}\right)+\mathrm{e}(\mathrm{t})$

$\mathrm{A}(\mathrm{q})=1+\mathrm{a}_{1} \mathrm{q}^{-1}+\ldots \ldots+\mathrm{a}_{\mathrm{n}_{\mathrm{a}}} \mathrm{q}^{-\mathrm{n}} \mathrm{a}$

$B(q)=b_{1}+b_{2} q^{-1}+\cdots+b_{n_{b}} q^{-n} b+1$

$\mathrm{q}^{-1} \mathrm{u}(\mathrm{t})=\mathrm{u}(\mathrm{t}-1)$

Figure 2 shows the ARX model structure. The block accepts two inputs, corresponding to the measured input-output data for estimating the model. The first input is Input signal and second input is output signal. The ARX Estimator block outputs a sequence of multiple models (idpoly objects), estimated at regular intervals during the simulation[8].

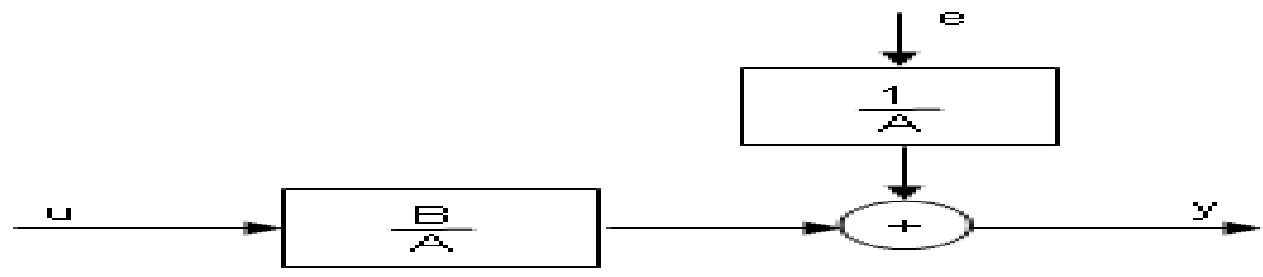

Figure 2: The ARX model structure .

\section{III.SYSTEM IDENTIFICATION}

System identification (SI) is the art and science of building mathematical models from measured input output data[8]. In order to obtain ARX model from input-output data, the Mat-lab System Identification Toolbox is used in the process of SI with identified involves the following four

steps:

1. Importing data into ident. from the workspace and substitute the input-output into it.

2. selecting time domain data in import data Window.

3. Preprocessing data (or preparing the data for estimation) where data have been divided into working and validation data using select range.

4. Estimating models based on the working data set. This is use to generate dynamic linear models with different structures, orders, and delays. A model structure characterizes the relationship between the input and output data, and between unknown noise sources and the output data.

5. Analyzing the model, where there are six views for examining models that are model output, model residual, transient response, frequency response zeros and poles as well as noise spectrum.

\section{IV.PARTICAL SWARM OPTIMIZATION ALGORITHM}

Particle swarm optimization, first developed by Kennedy and Eberhart [9] is one of the modern heuristic algorithms. It was inspired by the social behavior of bird and fish schooling and has been found to be robust in solving continuous nonlinear optimization problems. This algorithm is based on the following scenario: a group of birds are randomly searching food in an area and there is only one piece of food. All birds are unaware where the food is, but they do know how far the food is at each time instant. The best and most effective strategy to find the food would be to follow the bird which is nearest to the food. Based on such scenario, the PSO algorithm is used to solve the optimization problem. In PSO, each single solution is a "bird" in the search space; this is referred to as a "particle". The swarm is modeled as particles in a multidimensional space, which have positions and velocities. These particles have two essential capabilities: their memory of their own best position and knowledge of the global best. Members of a swarm communicate good positions to each other and adjust their own osition and velocity based on good positions according to (3)[11].

$$
\mathrm{v}(\mathrm{k}+1)_{\mathrm{i}, \mathrm{j}}=\mathrm{w} \cdot \mathrm{v}(\mathrm{k})_{\mathrm{i}, \mathrm{j}}+\mathrm{c} 1 \cdot \mathrm{r} 1\left(\mathrm{gbestj}-\mathrm{x}(\mathrm{k})_{\mathrm{i}, \mathrm{j}}\right)+\mathrm{c} 2 \cdot \mathrm{r} 2\left(\mathrm{pbestj}-\mathrm{x}(\mathrm{k})_{\mathrm{i}, \mathrm{j}}\right)
$$

$\mathrm{x}(\mathrm{k}+1)_{\mathrm{i}, \mathrm{j}}=\mathrm{x}(\mathrm{k})_{\mathrm{i}, \mathrm{j}}+\mathrm{v}(\mathrm{k})_{\mathrm{i}, \mathrm{j}}$

Where:

$\mathrm{v}(\mathrm{k})_{\mathrm{i}, \mathrm{j}}$ : Velocity of particle $\mathrm{i}$ and dimension $\mathrm{j}, \mathrm{x}(\mathrm{k})_{\mathrm{i}, \mathrm{j}}$ :Position of particle i and dimension $\mathrm{j}$

c1,c2: Acceleration constants, w : Inertia weight factor ,r1,r2: Random numbers between 0 and 1 , pbest: Best position of a specific particle, gbest: Best particle of the group.

The figure 3 shows the flow chart of a basic PSO[11]. 




Figure 3: The flow chart of a basic PSO.

\section{VI . INTERVAL FUZZY TYPE - 2}

The structure of a type-2 FLS is shown in figure 4. It is similar to its type-1 counterpart, the major difference being that at least one of the fuzzy sets in the rule base is type-2. Hence, the output of the inference engine is type-2 sets and a type-reducer is needed to convert them into type- 1 sets before defuzzification can be carried out[12].

\section{A. Inference .}

Fuzzy controller

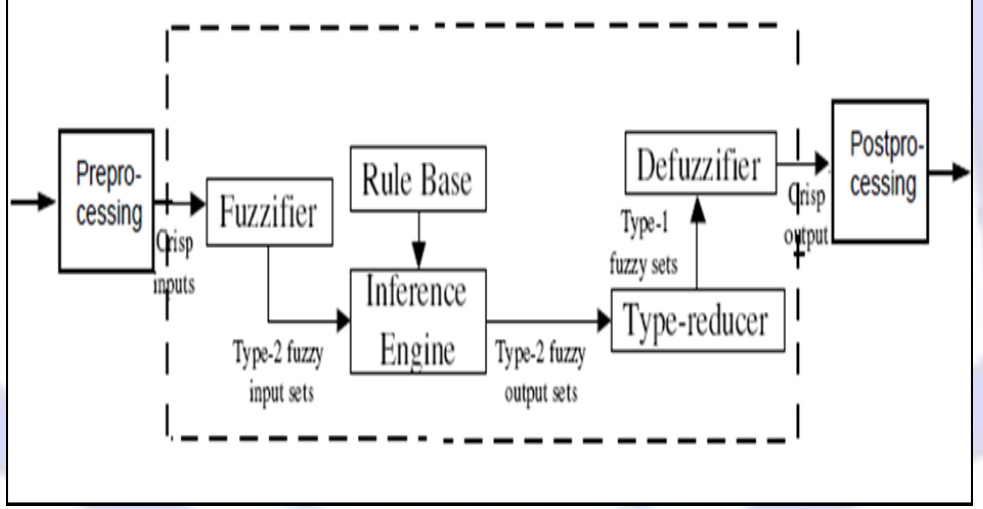

Figure 4: Structure of atype-2 FLS.

An interval type-2 FLS is employed[4]. "Interval" means that the input/output domains are characterized by interval type-2 sets [4], whereby the membership grades of all elements in the FOU (secondary membership grades) area nifty. The inference engine then matches the fuzzy rules in the rule base. To compute unions and intersections of type-2 sets, compositions of type-2 relations are needed. Just as the sup-star composition is the backbone computation for a type- 1 FLC, the extended sup-star composition is the backbone for a type-2 FLC [3].

\section{B. Type-reduction and defuzzification}

The output of the inference engine is a type-2 fuzzy et, it must be type-reduced before the defuzzifier can be used to generate a crisp output. This is the main structural difference between type-1 and type-2 FLCs. The most commonly used type-reduction method is the center-of-sets type-reducer, which may be expressed as [3] .

\section{V .PROPOSED VARIABLE EDGES OF FOU}

The variable edges of FOU are proposed for error uncertainty are proposed in such away that the range of error uncertainty for one side differs from the range of error uncertainty for the other side depending on actual given uncertainty. Table 1 represents the comparison between the variable edges of FOU and fixed edges of FOU for the same DC motor .The uncertainty in the primary memberships of a type -2 fuzzy set, $\widetilde{A}$, consists of abounded region that we call the abounded footprint of uncertainty(FOU) $\quad$.It is the union of all primary memberships ,i.e., 
In figure 5 the shaded region in the FOU for the a type -2 fuzzy set. The primary memberships, $\mathrm{J}_{\mathrm{x} 1}$ and $\mathrm{J}_{\mathrm{x} 2}$, and their associated secondary memberships functions $\mu_{\widetilde{\mathrm{A}}}\left(\mathrm{x}_{1}\right)$ and $\mu_{\widetilde{\mathrm{A}}}\left(\mathrm{x}_{2}\right)$ are shown at the two points $\left(\mathrm{x}_{1}\right)$ and $\left(\mathrm{x}_{2}\right)$. A FLC usually embeds the intuition and experience of a human operator and sometimes those of designers and researchers. While controlling a plant, a skilled human operator manipulates the process input (i.e. controller output) based on with a view of minimizing the error within shortest possible time. The controlled variable of fuzzy controller is $u(t)$.Once the fuzzy controller inputs and outputs are chosen, one must think about the membership functions (MSFs) for these input and output variables.

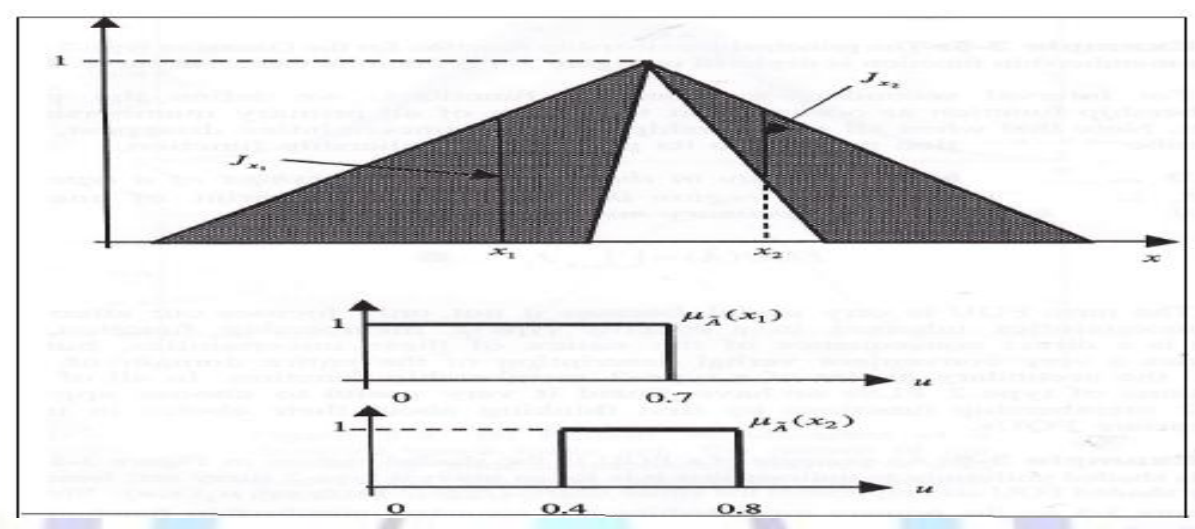

Figure 5: Membership function of FLCT2

In this paper, all membership functions for the conventional fuzzy controller inputs (e and $\Delta e$ ) and the controller output are defined on the common normalized domain $[-1,1]$. We use uniform triangles (with different FOU of MFs) with equal base and overlap with neighboring MFs. The figure 6 error of memberships functions. This is the most natural and unbiased choice for MFs. The figure 7. shows the real output of dc motor but the figure 8 shows outputs of dc motor when inputs impulse.

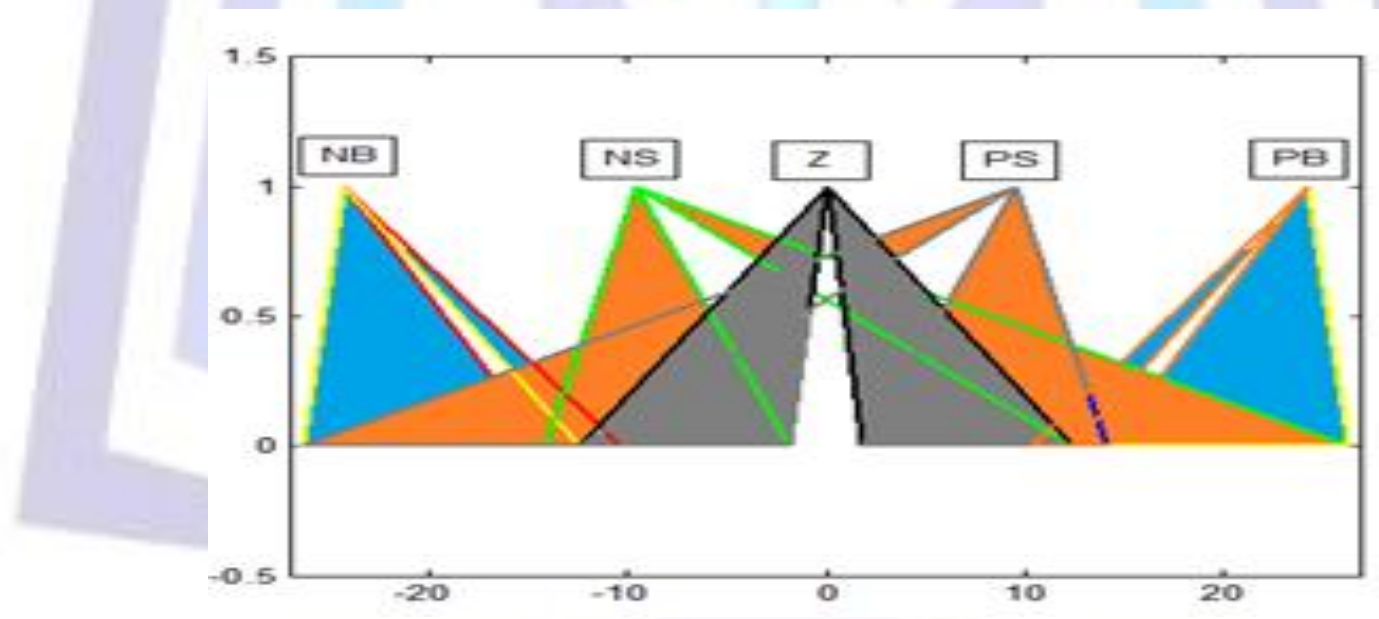

Figure 6: Memberships functions of error.

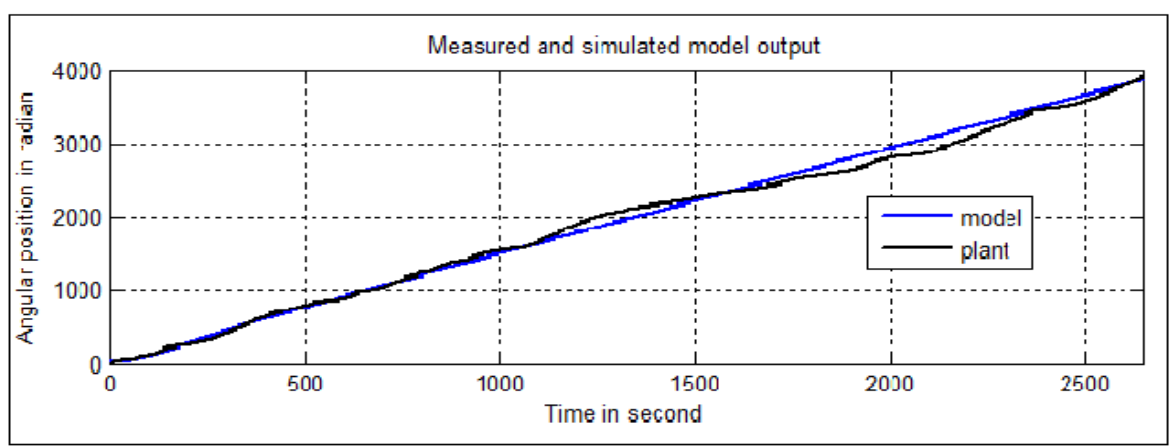

Figure 7: Measured and simulated model output using $10 \mathrm{~ms}$ sampling time. 


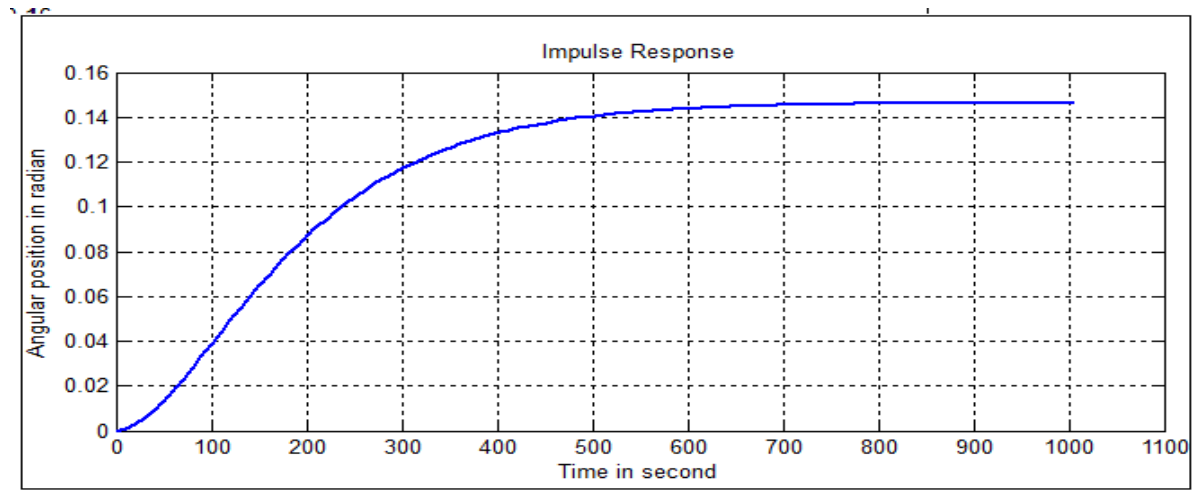

Figure 8: Impulse response of DC motor .

(with different FOU of MFs ) with equal base and overlap with neighboring MFs. This is the most natural and unbiased choice for MFs. The actual control input voltage for the main fuzzy controller (In the case of PI-type FLC) can be written as

$$
\mathrm{u}(\mathrm{k})=\mathrm{u}(\mathrm{k}-1)+\Delta \mathrm{u}(\mathrm{k})
$$

Where $\mathrm{k}$ is the sampling instant, is the crisp at $\mathrm{k}$ sampling instant and is the incremental change in controller output . showed that an IT2 fuzzy-PI (or the corresponding PD) controller is equivalent to a nonlinear PI (or PD) controller with variable gains and control offset[13].

\section{SIMULATION}

In this section. The identified parameters of the electric DC motor represented in the following transfer function .

$$
\frac{\Theta(s)}{V(s)}=\frac{0.093803}{s\left(0.00069455 s^{2}+0.052708 s+1\right)}
$$

\section{A. Experiment Analysis of Fuzzy Type-1 \& Fuzzy Type-2 without PSO.}

Simulation experiments under different operation status is carried out based on the for established model and performance comparison with IT2FLC and conventional type-1 fuzzy controller is made. The two curves in figure 9 are the simulation curves of the rated running state for DC motor respectively under the control of conventional type-1fuzzy controller and the type-2 fuzzy controller. For a clear comparison between the conventional fuzzy controller and the clustering based fuzzy controller, several performance measures such as peak overshoot (\%OS), settling time, rise time, integral absolute error (IAE) and integral-of-time-multiplied-absolute error (ITAE) are computed as shown in table 1. Using fuzzy type-1and type-2 controller, the rise time and settling time not good whereas for other measures, both the controllers give approximately the same performance.

\section{B. Fuzzy Type-1 \& Fuzzy Type-2 with PSO.}

In this section, DC motor is used in simulation. Figure 10 compares the simulation results of the two controllers when the external disturbance is zero. The performance of the two controllers is listed in table 2. Observe that PSO type-1 FLC has a noticeable overshoot and a slower convergence to the set point in comparison to PSOIT2FLC. Clearly, the PSOIT2FLC has zero overshoot. It is easy to see that PSOIT2 FLC has a faster settling time than PSO type-1 FLC. However, under disturbance, the performance of the scheme shows improved results. Figure 11 shows the zoom of response of the system with a $30 \%$ disturbance applied at $\mathrm{t}=0.36 \mathrm{sec}$. Table 3 shows the values of peak overshoot, settling time, IAE and ITAE computed under this condition. At the time $\mathrm{t}=0.36 \mathrm{sec}$, the external torque is decreased by a step of $25 \%$ Figure.12. The system again reaches the steady state after transient period. Table 4 shows the values of peak overshoot, settling time, IAE andITAE computed under this condition. The illustrated figures verify that a significant improvement has been achieved using the proposed Particle swarm optimization (PSO)type-2 fuzzy controller.



Figure 9: Response of T1FLC \& T2FLC OF DC motor 
Table 1. Numerical Result Of Experiment On DC Motor Without Disturbance(Fixed Gain and Fixed FOU).

\begin{tabular}{|c|c|c|c|c|c|}
\hline Controller & MP\% & ts(sec) & $\operatorname{tr}(\mathbf{s e c})$ & ITAE & IAE \\
\hline T1FLC & 30.43 & 0.298 & 0.039 & 28.652 & 19.229 \\
\hline T2FLC & 18.37 & 0.595 & 0.035 & 22.98 & 15.42 \\
\hline
\end{tabular}

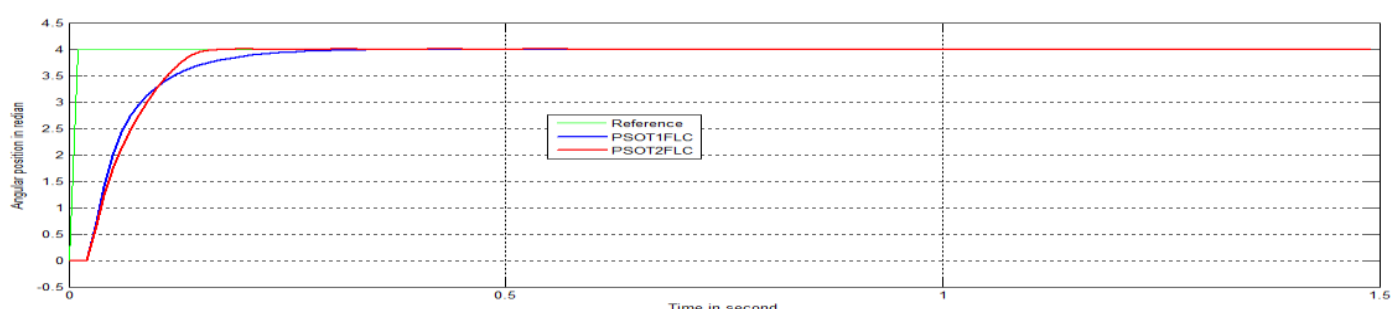

Figure 10: Response of T1FLC \& T2FLC of DC motor without disturbance.

Table 2. NUMERICAL RESULT OF PSO ON DC MOTOR WITHOUT DISTURBANCE(Variable Gain and Variable FOU).).

\begin{tabular}{|c|c|c|c|c|c|}
\hline Controller & MP\% & ts(sec) & $\operatorname{tr}(\mathrm{sec})$ & ITAE & IAE \\
\hline PSOT1FLC & 00.00 & 0.475 & 0.124 & 21.23 & 19.14 \\
\hline PSOT2FLC & 00.00 & 0.171 & 0.108 & 20.05 & 19.01 \\
\hline
\end{tabular}

Figure 11: Response of PSOT1FLC \&PSOT2FLC on DC motor with disturbance .

Table 3. Numerical Result Of Simulation On DC Motor With Comparison With Disturbance.

\begin{tabular}{|c|c|c|c|c|}
\hline Controller & MP\% & ts $(\mathrm{sec})$ & ITAE & IAE \\
\hline PSOT1FLC & 00.00 & 0.685 & 24.7176 & 23.130 \\
\hline PSOT2FLC & 00.00 & 0.471 & 17.8136 & 17.616 \\
\hline
\end{tabular}

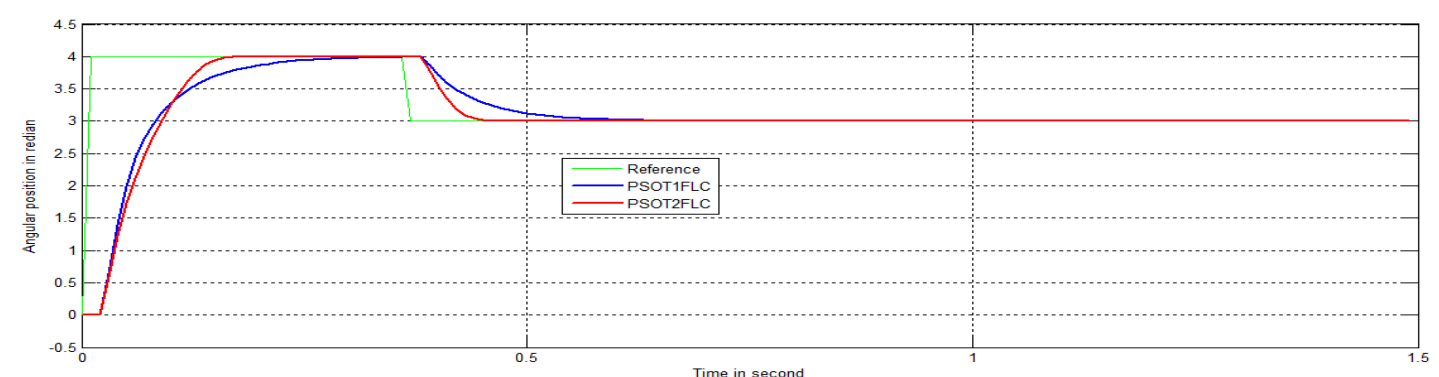

Figure 12:Response of PSOT1FLC \&PSOT2FLC on DC motor sudden decrease in position. 
Table 4. Numerical Result Of Simulation On DC Motor With Comparison With Sudden Decreased Disturbance .

\begin{tabular}{|l|l|l|}
\hline Controller & ITAE & IAE \\
\hline PSOT1FLC & 22.232 & 19.154 \\
\hline PSOT2FLC & 22.053 & 19.011 \\
\hline
\end{tabular}

Initially the motor is operated at the steady state. At the time $t=0.36 \mathrm{sec}$, an increased step of $25 \%$ of initial set point . As shown in Figure 13 the motor position tracks the new set point after a transient period. Obviously, the external torque is assumed constant. Table 5 show the values of IATE and IAE under these conditions. Comparisons with the conventional fuzzy controller indicate the improvement achieved

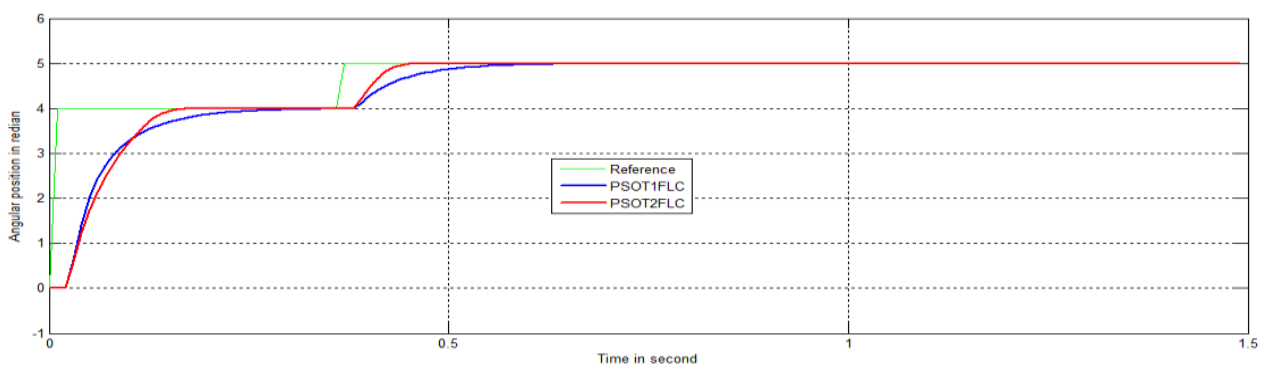

Figure 13. Response of PSOAT1FLC \&PSOT2FLC on DC motor sudden increased in position .

Table 5. Numerical Result Of Simulation On DC Motor With Comparison With Sudden Increased Disturbance.

\begin{tabular}{|c|c|c|c|c|}
\hline Controller & MP\% & ts(sec) & ITAE & IAE \\
\hline PSOT1FLC & 00.00 & 0.4600 & 36.8607 & 24.7387 \\
\hline PSOT2FLC & 00.00 & 0.7300 & 34.1576 & 22.9246 \\
\hline
\end{tabular}

\section{Fuzzy Type-1 \& Fuzzy Type-2 with Random Noise PSO.}

In this section, we show in figure 14 the simulation results for control of DC motor using both the PSO type-2 fuzzy controller and the conventional fuzzy controller when used random noise reference signal. To further investigate the characteristics of the FLCs, the control surfaces of the two FLCs are generated and shown in figures. 15,16. The control surfaces of the PSOT1 FLCs and PSOT2FLCs are smoother. The control surfaces provide further evidence that there will not be significant performance deterioration when the proposed T2 FLC is used in place of a traditional type-1 FLC where all the input sets are type-2 MFs.

\section{Experiment Analysis of Proposed Variable Edges Of FOU.}

In this section, we show in figure 17 the simulation results for control of DC motor using type-2 fuzzy controller for four cases fixed gain (scaling factors ) and fixed FOU, variable gain and fixed FOU ,fixed gain and variable FOU and variable gain and variable FOU. Table 6 . Show the numerical result of simulation on DC motor with comparison between gain and FOU for FLCT-2.

\section{CONCLUSION}

In this paper, The PSOFLCT2 has been proposed for position control of DC motor. Performance of the proposed PSOFLST2 was also compared with corresponding conventional PSOFLCs with respect to several indices such as rise time, settling time, maximum peak overshoot (MP\%), integral of absolute error (IAE). and integral time of absolute error (ITAE). 


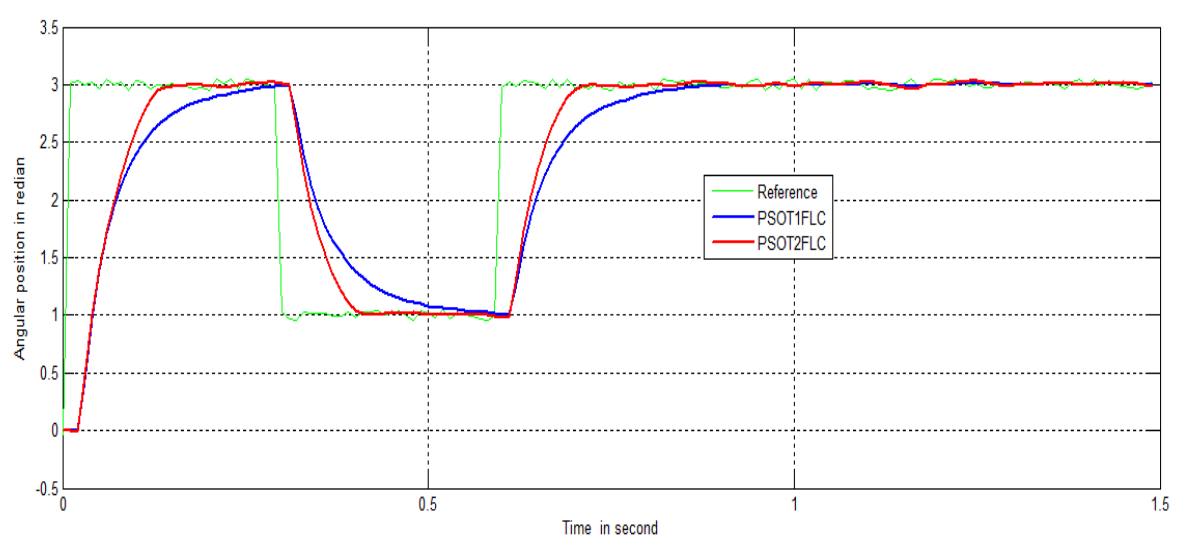

Figure 14: Response of PSOT1FLC \&PSOT2FLC on DC motor with random noise.

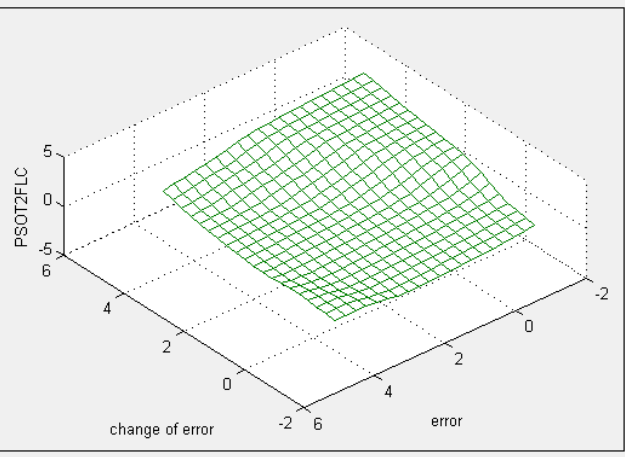

Figure 15: Complete control surface of PSOT2FLC

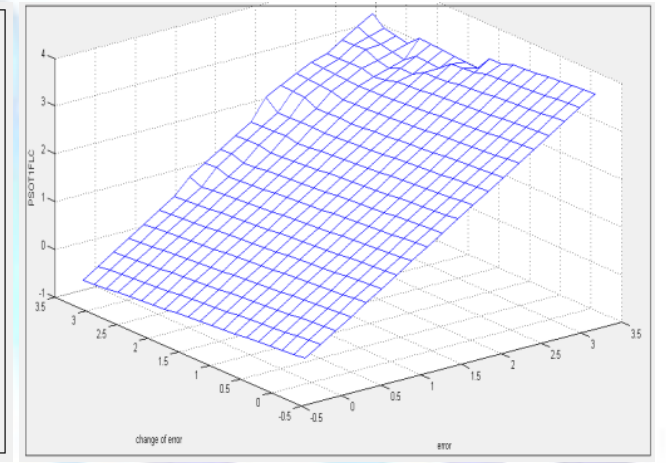

Figure 16:Complete control surface of PSOT1FLC

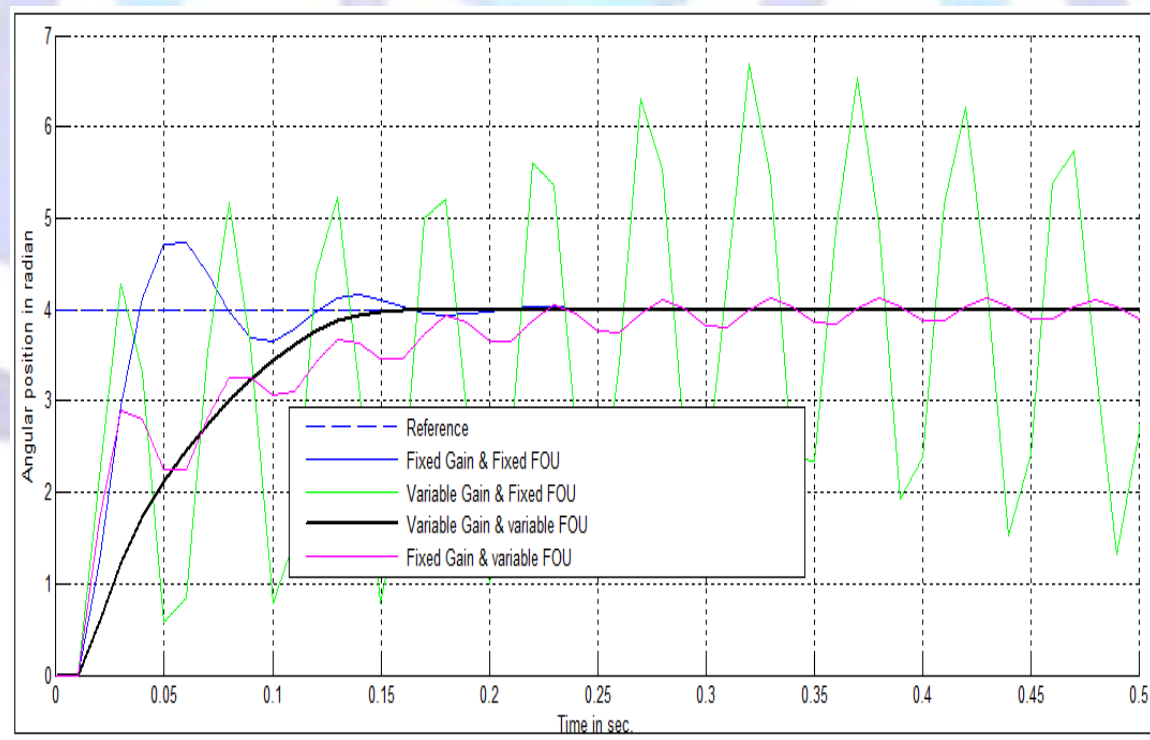

Figure 17: Comparison between Gain \& FOU for FLCT-2. 
Table 6. Numerical Result Of Simulation On DC Motor With Comparison Between Gain and FOU For FLCT-2.

\begin{tabular}{|c|c|c|c|c|}
\hline Pefformance & FixicGoilh & Var:Gaili & Vur:Gaili & Fin:Gail \\
\hline meswerwentrats & Fit: $\mathrm{POU}$ & Fit:FOU & Var: $\mathrm{FOC}$ & Var:FOC \\
\hline $\operatorname{tr}(s \mathrm{SeC})$ & 0.05 & 0.03 & 0.1 & 0.13 \\
\hline If $(B P C)$ & 0.21 & 10 & 0.14 & 0.62 \\
\hline $\mathbb{I} \mathbb{P}_{0}$ & 18 & 69 & 0.0 & 0.3 \\
\hline IAR & 24.25 & 24256 & 15,42 & 301.18 \\
\hline IIAD & 36.13 & 361.41 & 22,98 & 44.98 \\
\hline
\end{tabular}

The simulated results show that, using a type-2 FLC in real world applications can be a good option since this type of system is a more suitable system to manage high levels of uncertainty, as we can see in the results shown in tables $2,3,4$ and 5. Simulation results indicate that the performance of the PSO FLCT2 will better. That is mean the system will sense for change the value of IAE and ITAE . The results demonstrate that a type-2 FLC can outperform type-1 FLCs that have more robustness design parameters. The main advantage of the type-2 FLC appears to be its ability to eliminate persistent oscillations, especially when unmodelled dynamics were introduced. This ability to handle modeling error is particularly useful when FLCs are tuned offline using PSO and a model as the impact of unmodelled dynamics is reduced .Finally the table 6 it is very good response of DC motor when using variable gain and variable FOU .

\section{REFERENCES}

[1] Zadeh, L. A“Fuzzy sets. Information and Control”. 8, 338-353 (1965).

[2] John, J. and Langari, R. " Fuzzy Logic Intelligence, Control and Information" .Prentic Hall, Englewood Cliffs, NJ, 1998.

[3] King, P. and Mamdani, E., "The application of fuzzy control to industrial process " Automatica 13, 35-242(1977).

[4] Mendel, J. M., “ Rule-Based Fuzzy Logic Systems: Introduction and New Directions” Prentice-Hall, Englewood Cliffs, NJ, 2001.

[5] Liang, Q. and Mendel, J. M., “Interval type-2 fuzzy logic systems: theory and design”. IEEE Trans. Fuzzy Syst. 8 (5), 535-550 (2000).

[6] Liang, Q. and Mendel, J. M., " MPEG VBR video traffic modelling and classification using fuzzy technique”.IEEE Trans. Fuzzy Syst. 9, 183- 193(2001).

[7] Kama,Mahanijah,Nasirah,and Norhayati “System Identification of discrete Model for DC Motor Positioning",control and signal processing ,2008, ISSN: 1790-5117.

[8] Jakob k.H ,Niels K.P.,Sten B.J. and John B. J. "ARX -Model based Predictive Control with Tracking" ,20 $20^{\text {th }}$ ESCAPE20, ,2010.

[9] Kennedy, J. and R. Eberhart, , "Particle swarm optimization," in Proc.IEEE int. conf. Neural networks, Perth, Austrailia, IV: 948,1995.

[10] Mohammed Z. Al-Faiz,Sadeq, "Partical Optimization Based Fuzzy- Neueal Like PID Controller for TCP/AQM Router,Intelligent Control and Automation,3,71-77, 2012..

[11] kazem,Mohamad,Mahais,andAhmed, "Desi Fuzzy Logic Speed Controller for D Motor with Partical Swarm Optimization PSO Algorithm",Australian Journal of Applied Sciences,5(12):1283-1290,2011ISSN 19918178,2011.

[12] Mohammed Z. Al-Faiz,Ahmed A. Oglah "Type-2 Fuzzy Logic Controllers Based Genetic Algorithm for the Position Control of DC Motor, Intelligent Control and Automation,4,108113,2013

[13] X. Du and H. Ying, "Derivation and analysis of the structures of the interval type-2 fuzzy- PI and PD controllers", IEEE Trans. On Fuzzy System, vol. 18, no. 4, pp. 802-814, 2010. 